In this connexion I may refer to the case which I have already mentioned of the Odessa Jewess who had a persistent visual hallucination to the left, and the traumatic meningitis on the right side of the brain had involved the whole region of the angular grrus.

These cases all speak with the same clear significance. It is different from the diminution of the remaining halffield in some cases of hemianopia, which was the evidence on which I relied in my Manual, as justification of the assumption in man of the higher visual function of the region of the angular gyrus. The higher the level of function the more complex its representation may be, and we may hesitate to reject entirely that of which the evidence may still seem imperfect.

\section{LATENT CHOREA: A CONTRIBUTION TO THE STUDY OF SYDENHAM'S CHOREA.}

By REGINALD MILLER, M.D. LoND., M.R.C.P. LoNd., PHYSICLAN TO OUT-PATIENTS, PADDINGTON GREEN OHILDREN'S HOSPITAL; ASSISTANT PHYSICIAN TO OUT-PATIENTS, S'T. MARY'S HOSPITAL.

$r$ Is the most important question of the prevention of rheumatic heart disease all are agreed as to the prime necessity of the recognition of the earliest manifestations of the rheumatic infection, and to this end the possible rheumatic mature of such conditions as tonsillitis, " growing pains," and cardiac dilatation has been emphasised by many authors whose views have rightly met with almost universal acceptance. It has seemed to me that for this purpose the study of chorea has been unduly neglected, and it is the object of this communication to emphasise what may be the earliest signs of this type of rheumatism and to draw one or two deductions from the considerations put forward.

At the outset I must offer some defence for the term "latent chorea" with which I have ventured to head this paper. To it there is the obvious objection that in any patient chorea either is present or is absent; nevertheless, it is a convenient name under which to describe cases I welieve to be instances of chorea, but which would certainly not be recognised as such. I shall here therefore by "latent chorea" mean such a condition as I am attempting to show to be the earliest form of nervous rheumatism, and by "chorea" the well-known disease with (amongst other symptoms) its disorders of movement, characteristic and obvious. We may perhaps with advantage study first the common symptoms which are seen in a case of chorea, noticing especially how they might be expected to appear in their slightest and earliest forms. They may be divided into motor, mental, and atonic.

The motor symptoms consist of the perpetual, irregular, and purposeless movements of the limbs, which have been well described as those of "exaggerated fidgetiness" (Sturges). In addition there may be noted incoördination, due in part, I think, to cerebellar involvement, which assist in rendering voluntary movements clumsy, and in bad cases quite futile. In the trunk there are seen squirming movements and often irregular and incoördinate action of the respiratory muscles, so that the breathing may be in turn thoracic, abdominal, or normal in type. Long-drawn sighs, such as are heard in nervous women, are very common. In the face the movements show themselves, as they must, in various emotional expressions, such as those of pleasure, dislike, fear, or surprise, which flit across the countenance. These may not in severe cases, as far as car be gathered, indicate any corresponding emotion on the part of the child but often in the slighter forms of the disease they do express (or rather over-express) the mental attitude of the moment In addition there are movements of the jaw, tongue, and lips which may cause the familiar choreic "clucking." Pupillary changes are not uncommon and are of some interest to us here. Dr. F. Langmead ${ }^{1}$ has described hippus, inequality, and eccentricity of the pupils, and to these may be added irregularities in shape. As I have seen them these are usually found in the early stages of chorea. The displacement of the pupil, in my experience, is always upwards and inwards. Dr. Langmead pointed out that they were seen

I THE LANCET, Jan. 18th, 1 08 , p. 154 in cases of chorea, but also, although less frequently, in patients suffering from acute rheumatism but not diagnosed as instances of chorea. It must, however, be acknowledged that in nervous but non-rheumatic children these pupillary abnormalities are sometimes found, and I cannot help regarding them as evidence of nervous instability rather than of any type of rheumatic infection.

Reducing these motor phenomena of chorea down to their slightest forms, such as we might surmise to be present at the very outset of the disease, we should expect to find general fidgetiness only slightly exaggerated, clumsiness in voluntary movements (especially in the finer ones of the fingers), and unnecessary and excessive emotional movements of the face. To these might be added, perhaps, abnormalities of the pupils and the occurrence of occasional sighing respirations of a nervous type. All of these symptoms might be taken to denote merely an extremely neurotic child.

Of sensory changes in chorea I have not found more than a trace. Pharyngeal anæsthesia, the only one I have looked for often, I have noted but twice. Considering how comparatively common this is in neurotic young adults, I had expected to find it in chorea more frequently than I did. Its absence may perhaps be explained by the chronic tonsillitis and general faucial injection which are so usual in choreic patients.

The mental symptoms of chorea are of great importance, and it is not too much to say that they have not received the recognition that is due to them. They are so constantly present and so much a part of the disease that in many ways chorea might well be looked upon as a mental rather than a motor disease. Yet the mental side of the disease has been so neglected that some authors have gone the length of describing a condition which they term " hemi-chorea." With the severe forms of choreic insanity, such as a raving delirium, agitated melancholia, dementia or coma, we are not here specially concerned. What I wish to emphasise particularly are those slighter types of mental perversion which are seen in one form or another in all choreic children. These are mental depression, excitability, emotionalism, in. attention, loss of memory, or signs of diminished control as shown by outbursts of passion, unnatural fear, uncontrollable laughing or crying. Often indeed, if the history of the onset of chorea be carefully traced, it is found that such symptoms as these are noted prior to the development of definite movements. As a rule early in the disease the mental attitude is one of depression, while during convalescence it becomes one of exaltation. This will be referred to later in the study of the nervous symptums (latent chorea) in cases of acute and convalescent rheumatism. In their slightest forms, therefore, these symptoms of chorea would appear as those of mental instability as shown by excitability, fretfulness, inattention, and attacks of passion or crying; such symptoms as might be found in a neurotic, spoilt, but nonrheumatic child.

The atonic symptoms of chorea, paresis or paralysis, are usually present only in the severer forms of the disease and, as a rule, are late in their appearance. Sometimes the paralysis is so marked and accompanied by such rapid wasting as to suggest that the anterior horn cells have been attacked by the infection. I mention this because chorea is so often spoken of as cerebral rheumatism, whereas it may quite possibly be a disease of the whole of the central nervous system in which involvement of the cerebrum gives rise to the earliest and grossest perversions of function. It is obvious that the atonic symptoms in their lesser forms will not be recognisable as choreic, and thus are of no aid to us in approaching the disease from our present standpoint.

Before passing on I must make mention of some of the other signs of the rheumatic infection, particularly as they occur in cases of chorea. Over tonsillitis, " growing pains," muscular rheumatism, and subcutaneous nodules we need not pause; their significance is well appreciated. Arthritis rarely co-exists with well-marked choreic movements as has long been recognised. Perhaps this is owing to the stimulus to complete motor control set up by a painful joint.

The heart, as has been taught by Dr. D. B. Lees, shows dilatation as its earliest response to active rheumatism. This is only to be detected by careful percussion of the deep cardiac dulness. In addition the pulse is quickened and the heart excitable. Reduplication of the first apical sound is of some interest: it is not uncommon in dilated hearts and 
in those of children who are nervous under examination, and where these two factors are both present, as in chorea, it is so common as to be almost the rule. Usually it passes off after a few days' rest in bed. Irrogularity of the heart is very frequent in chorea, but is not so common as is the reduplicated and rather slapping first apical sound. The pulmonary second sound is usually augmented and frequently doubled. In the earliest stages of cardiac dilatation there is no systolic bruit at the apex.

Anæmia is the rule in all rheumatic infections, and it is of interest as to some extent it is an index to the progress of the case. It is very prone to remain in spite of treatment by iron should the infection be quieted but not destroyed. It is frequently seen associated with a rather characteristic pink flush on the cheek. Pain in the epigastrium or in the left side of the chest is a symptom often found in rheumatic children, and I have seen it so severe as to be the cause of the child's visit to hospital. It may occur after food but often is independent of meals. Epistaxis is not uncommon in rheumatic children with slight cardiac affections, as Dr. Sidney Phillips has pointed out.

Headache is an interesting symptom. It is, of course, a common associate of anæmia, but in children is more of ten than not rheumatic in origin. Goodhart ${ }^{2}$ states that in 33 cases of headache 23 were of rheumatic stock. Most commonly this symptom is seen in the early stages of chorea, as Dr. G. F. Still ${ }^{3}$ has noted, and so may be regarded not oniy as rheumatic but as evidence in many cases of an early intracranial infection. It will be remembered that Dr. F. J. Poynton and Dr. Gordon M. Holmes ${ }^{4}$ have found vascular engorgement of the pia-arachnoid among other changes in chorea. Thinking that the headache might be due to meningeal cedema, for an excess of cerebro-spinal fluid is usually present in chorea, I tried the effect of calcium lactate as suggested by Sir A. Wright. The symptom was, however, completely unrelieved by this measure, while as a rule it is easily amenable to treatment by sodium salicylate. It is important to recognise that while headache is a frequent result of rheumatism in children, it is rarely produced in them by the salicylate group of drugs.

Sweating of the palms of the hands is very constantly seen in children with any form of rheumatism, but to a less extent is not uncommon in others as well.

I have described in some detail symptoms that must be familiar to all who have studied rheumatism in childhood, partly because any emphasis that is laid upon the fact that chorea is not a disease of the motor system alone is not amiss, and partly because in the delicate task of tracing so composite a clinical condition as this to its earliest manifestations it is necessary to put clearly what are the symptoms that might be expected to be present. It will be seen that I have for the most part omitted the occasional and rare phenomena and have referred to those which are seen if looked for in case after case.

We may expect, then, that a patient showing the earliest signs of chorea would appear to us in somewhat the following light. The child would be pale, fidgety, and in the finer movements of the limbs clumsy; he would be nervous, easily frightened and upset, affectionate but passionate when crossed, excitable but readily exhausted, unable to concentrate his attention on anything for more than a moment, and hence getting into trouble at school, particularly over his sums. The heart will almost certainly be dilated and excitable, with reduplication of the first sound at the apex and possibly irregularity of rhythm. The hands will be moist, and the pupils may show various abnormalities. Headache and pain in the left side or epigastrium might also be present. On inquiry there would probably be obtainahle a history of sore-throats or growing pains, or of a strong rheumatic taint in the family. In addition there might be symptoms that I have not yet mentioned. From the general nervous instability as seen in the earliest stages of chorea may arise many so-called functional nervous disorders, such as disturbed sleep, night terrors, somnambulism, acquired enuresis, habit-spasms, lienteric diarrhoea, and the like.

I may now proceed to describe how this condition of mental and physical ill-health, which is rheumatic in origin and which I have termed "latent chorea," is met with in children. It may be seen in three groups of cases, and I give them, not in order of their importance, but in that in

Goodhart and Still : Diseases of Children, seventh edition, p. 661. ${ }^{3}$ Common Disorders of Childhood, p. 458 which they are most conveniently studied. These are (1) in children with obvious acute rheumatism; (2) in children convalescert from rheumatism and chorea ; and (3) in children without any very obvious rheumatic symptoms.

1. Latent chorea associated with acute rhenmatism. - Children with acute rheumatism of the joints, muscles, or heart show as a rule that the nervous system has not escaped. I have heard the saping attributed to a physician eminent among those who study the diseases of children that "nearly all rheumatic children have chorea." Certainly this is so if chorea is recognised in its earliest forms. If it is taken to be a disease of disordered movements only, and these are tested for by the coarse method of making the child hold its hands out straight in front of it, then the disease cannot be said to exist in all rheumatic children. A more delicate test for these movements is required. Watch how the child fidgets as one approaches the bed, how jerkily the hand is withdrawn from under the berlclothes to shake hands, or how the clumsiness in action is shown as the child pulls up its bed-dress for its chest to be examined; in such ways the traces of choreic movements are clearly seen. Often, indeed, a definite attack of chorea can be watched developing out of such sight signs as these. Another test which I have found of use is that noticed when looking for pupillary changes-namely, the child's inability to keep its eyes fixed on an object for more than a second or two. As Dr. Langmead pointed out, abnormalities of the pupils are not uncommon in these children. On the mental side also traces of chorea are quite evident. How depressed are children with acute rheumatism and this in the absence of pain. When admitted to hospital their trials are no greater than those of other children, but their unhappiness is much more severe. Often they can be found crying quietly with long convulsive sobs, the very picture of misery. This mental depression has often been noticed in cases of acute rheumatism, and has been attributed to the treatment by salicylates. But I have seen it many times where no such drug has been used, and I have seen children entirely free from it yet taking between 300 and 400 grains of sodium salicylate per diem, and am convinced. therefore, that this symptom of mental depression has, as have anæmia. cardiac "depression," and others, been erroneously ascribed to the treatment instead of to the disease. Salicylate of soda will, as Dr. Lees teaches, depress a child if allowed to produce nausea or vomiting, but not otherwise. In adults with acute rheumatism a feeling of intense misery is not seldom present and is not always attributed by the patient to pain. That it is not so marked as in children is explicable on the grounds that the nervous system is more stable in arlults than in young subjects and that in children all bacterial infections tend to become more generalised than is the case in adults.

At a Christmas entertainment in a children's ward I had once an excellent opportunity of noticing the nervous instability caused by rheumatism. One of the performers entered the ward dressed in a " property" monkey's skin. Most of the patients were delighted, but from some came immediate shrieks of terror, and I noted that those frightened included not only convalescent cases of chorea, but children with joint or cardiac rheumatism.

The recognition of latent chorea in cases of acute rheumatism adds another link to the strong chain of evidence binding rheumatism and chorea together as the result of one and the same infection.

2. Latent chorea in convalescence from acute rheumatism and chorea.-During convalescence from acute rh+umatism the signs of latent chorea are somewhat different from those just described. The main change is in the mental condition of the child, the morbid depression is succeeded by an unnatural mental exaltation. The convale-cent rheumatic child is a very delightful little person and in a ward is everyone's favourite. (I think no one will deny this.) He is affectionate, obedient, intelligent, and quick; ris wits are, in fact, considerably sharper than those of most children. His shyness has gone and he is now willing very quickly to become your friend. He is very prone to become overexcited at play and has to be lnoked after on that account. $\mathrm{He}$ is apt to take linerties with you, and in his excitement may be very rude in a guileless way. A word from one in proper authority, however, quicklv snbdnes him and may reduce him to tears of penitence; I do not think I ever saw him seriously punisher

In addition to these signs of mental instability the slight B B 2 
motor symptoms already mentioned are still present, but as the initial depression wears off a new facial movement makes its appearance. This is the quick smile of welcome seen on the approach of a visitor; pleasant enough in its way but far from convincing, a veritable "society smile." In cases of chorea it is often seen and indicates, I think, practically no emotion of pleasure, but during convalescence it does express in an exaggerated way the feeling of pleasure. It is very characteristic.

A patient recovering from chorea passes into exactly the same condition, and to one who has trained himself to recognise at sight the slighter forms of chorea it is often impossible to distinguish at a glance between the child who has rheumatic synovitis or slight heart trouble and one who is getting well from chorea. Lastly, under this heading comes an important consideration. This latent chorea of convalescence may depend on nerve.cells which have been damaged by a rheumatic infection which is passed and gone, but on the other hand-and this is specially to be feared where there are persistent anæmia and a regular slight nocturnal rise of temperature-it may be due to a still smouldering infection, one that is damped down but not destroyed.

3. Latent chorea nithout obvious symptoms of rheumatism.-It is to this class that I wish to call special attention, for by the failure to recognise it and its rheumatic origin we may lose a valuable opportunity of preventing the severer forms of heart disease.

Children suffering from this form of latent chorea may be brought to the doctor for various complaints. For the most part these are of a slight and indefinite nature. The mother may complain that the child is out of sorts, is languid, will often refuse to touch its food; in her own phrase, "I don't know what to make of him." Headache is a common symptom, and for this, I should imagine, these children not seldom find their way to the ophthalmic departments of hospitals. The mother may volunteer the fact that the child is very nervous but, as a rule, inquiry has to be made if there has been any change in the child's temperament, when it will be found that he has become excitable, fidgety, irritable, passionate, and timid. The patient may have become too frightened to sleep alone or to cross a street. Sometimes the child's pallor attracts the mother's attention, or it may be that symptoms referable to the cardiac dilatation, such as the feeling of being always tired or of the feet being too heavy to lift, cause the visit to hospital. Fidgetiness is rarely in these cases the chief complaint, but on inquiry the mother has usually noticed it, and may say that the boy is no longer able to play quietly by himself or the girl to sit at her sewing. In addition, the voluntary movements of the finer sorts have become clumsy. I have seen in these children the marks of needle pricks all over the three middle fingers of the left hand, while in an ordinary little girl who sews they are confined chiefly to the inner surface of the index and to the tip of the middle finger. Their mental fidgetiness is often shown by the fact that although previously good at school they have lately got into disgrace over their lessons, particularly their sums, and may even have been threatened with degradation to a lower class.

On the other hand, more definite symptoms arising from the nervous instability of these patients may cause the child to be taken to the doctor. The most common of these are talking (often doing sums) during sleep, difficulty in getting off to sleep, night terrors, somnambulism, acquired enuresis, lienteric diarrhœea, or habit spasms. These cannot be regarded as part of the chorew, but are rather of the nature of complicating symptoms; the chorea causes the nervous instability, which in its turn is responsible for the appear. ance of this group of disorders. The appearance in rheumatic children of such conditions as these has been noted by many authors.

The diagnosis of this type of chorea is often suggested at sight, partly by the peculiar pink flush of the patient's cheeks and partly by the general deportment of the child, the fidgetiness, the smiling, and the generally unbalanced nervous state. Such an impression needs careful confirmation by means of the examination of the patient's symptoms and physical signs. Of first importance is the question of sore-throats and growing pains, while headaches are of very constant occurrence. In 16 consecutive cases of latent chorea of this type I noted sore-throats in 13, growing pains in 9 , and headaches in 11 . Inquiries should be made into the family history for evidence of rheumatic fever or chorea in the parents or, a matter of greater importance, in brothers and sisters. As might be expected, an inherited neuropathic taint can often be traced. In a neurotic child the earliest symptoms of a mild rheumatic infection are likely to be those referable to the nervous system. Dilatation of the heart is in favour of a rheumatic infection, for this is the most common cause of such a condition in children.

We have, then, to decicle in any particular case if the con. dition is one of latent chorea or is simply an expression of nervousness in a neurotic but non-rheumatic child. A nervous child may show a considerable amount of fidgety movement-a microkunesis, Dr. F. Warner has termed it, and may be emotional and anæmic and may show slight dilatation of the heart. The symptoms of latent chorea can, as a rule, be distinguished from this state with fair ease They are of recent origin, the movements are rather different in type, and are associated with clumsiness in the finer voluntary movements, as in sewing. The impossibility of getting the child to fix the eyes on an object for more than a second or two is much more characteristically present in cases of latent chorea than in neurotic but non-rheumatic children. But sometimes it is difficult to decide between the two conditions; as Dr. Still" says, a nervous child "manifests a general fidgetiness which is easily mistaken for a slight chorea." Where such a difficulty arises, the question can usually be settled by inquiry into the matter of sore-throats and growing pains. Where these are, or have been, present, and especially where they are associated with dilatation of the heart, headaches, pain in the left side or epigastrium, moist hands, and where there is a marked family history of rheumatism, the diagnosis of latent chorea becomes increasingl probable. The diagnosis is not to be settled by the presence of any one of these points but by the coexistence of several of them.

1 do not wish to suggest that all children who are nervous, fidgety, and pale, and who show slight dilatation of the heart, wet hands, or pupillary abnormalities are the subjects of a rheumatic infection; in many such there is no evidence of this disease to be traced. But it is the main object of this paper to emphasise the fact that just such a condition of ill. health and nervous instability may be due, and in London is very commonly due, to a latent chorea. It is then a matter of some moment that the physician, confronted with a child suffering from various nervous symptoms, should bear in mind the frequency with which such disorders owe their origin to a rheumatic infection; for, to transpose Dr. Still's words quoted above, a child with a slight degree of chorea manifests a general fidgetiness (with others signs) which is easily mistaken for simple nervousness.

It might be suggested that what I have termed latent chorea is due to a rheumatic toxæmia, while chorea, fully developed, is due to a rheumatic infection of the central nervous system. While this may or may not be the case, it is a small point beside the important one of the recognition that the condition is rheumatic.

Lastly, the association between rheumatism and "nervousness" has been recognised for many years until it has become to be vaguely held that the infection is particularly prone to attack children of a neurotic temperament. It appears to me, however, that this association is much more properly explained for the great majority of cases by regarding the nervousness as a result of a mild and un. recognised infection. Given the infection, the symptoms of chorea, latent or fully developed, are more prone to appear in a neurotic than a normal child.

Conclusions.-1. That (rheumatic) chorea declares itself first by symptoms significant of general nervous instability. 2. That in dealing with children suffering from nervous disorders of many kinds special care should be taken to exclude the possibility of their having originated from a slight rheumatic infection. 3. That the well-known association between rheumatism and nervous instability is not to be explained by considering that the infection is specially prone to attack neurotic children, but by regarding the nervousness as in most cases the outcome of an infection already present (latent chorea). 4. That the mental depression and headache in rheumatic children are usually to be attributed to the disease and not to its treatment by salicylates. 5 . That 
the recognition of latent chorea in children suffering from obvious acute rheumatism affords strong evidence that chorea is a rheumatic condition.

Queen Anne-street, W.

\section{NOTES OF A CASE OF X RAY ULCERS CURED BY HILTON'S METHOD.}

\section{By AGNES F. SAVILL, M.A. ST. AND., M.D. GLASG., M.R.C.P. IREL.}

ASSISTANT L'HYSICIAN TO ST, TOHN'S HOSPITAL FOR DISEASES OF THF SKIN, LEMCESTER SQUARE.

A MARRIED woman, aged 30 years, consulted me at St. John's Hospital for Skin Diseases on Feb. 2nd, 1909, complaining of intense pain in two ulcers situated on the left shoulder and upper arm. The ulcers had appeared after prolonged treatment by $X$ rays for scleroderma, and the pain was so severe that she had not slept for over an hour at a time for nearly two years.

The patient was a sensible woman, able to give a clear account of her illness and the progress of her symptoms. Just after the birth of her first child in 1898 she had pain in the left breast, and a few weeks later she noticed the skin on the inner side of the breast had a white mark, which increased in size very slowly and spread over to the sternum. About four years later (1902) the left shoulder and upper part of the arm became affected similarly, and during the following year the whiteness and thickening of the skin gradually extended to the forearm. In 1903 she sought advice at one of the large hospitals in Great Britain and treatment by $X$ rays was ordered. Six months later the disease appeared on the outer aspect of the left thigh, and $X$ rays were administered to that patch also. Some time later she became aware that small patches had appeared on the back and on the chest under the left arm, and in the winter of 1908-09 patches appeared on the left side of the neck just above the clavicle.

History of the $X$ ray treatment and its results.-The treatment was administered almost daily for a period of two years, from 1903 to 1905 . The left shoulder was exposed to the rays for five minutes, the lower part of the arm for another five minutes. During this treatment of the arm she was in the habit of sitting with the elbow flexed, the hand resting on the shoulder, with the thumb tucked in under the first finger. The breast and the thigh were also exposed for about five minutes each. Thus the daily treatment lasted altogether about 20 minutes. Sometimes there was a degree of reaction, when she was given a week or two of rest until it had subsided. The reaction consisted of redness and soreness, not severe, and it occurred only on the upper left arm and shoulder, never on the breast or thigh. She believes that towards the latter part of the treatment it occurred about every six or eight weeks, and usually lasted only for about one week. In 1905, however, a very severe reaction occurred, which extended down as far as the elbow, and the left side of the face and the first and second fingers of the left hand also were affected. She decided not to have any more treatment. A year or so later she left that town and came to reside near London and was therefore unable to seek advice from her former medical men for the conditions which ensued. When the inflammation had subsided she noticed two small "pimples," one on the left shoulder, one about 2 or 3 inches lower on the upper arm. These "pimples" remained troublesome for two years (1905 to 1907); always catching in her clothing as she dressed and undressed and were very tender. They had a hard scaly top, and later became red and swollen around. About 1907 the scaly tops used to come off frequently, grow again, and again fall off. Then the tops failed to reform, and open sores were left beneath. A little lower down on the arm was a smaller pimple which, presumably, was not so much exposed to friction, because the patient's attention had not been drawn to it; the importance of this lesion will be referred to below. The two ulcers slowly increased in size and became intensely painful. The upper ulcer was never larger than the size of a shilling, the lower became as large as a fiveshilling bit, and was, she thinks, about $\frac{1}{2}$ inch deep; at no time was there much discharge. For two years (1907-09) she was unable to obtain relief sufficient to obtain more than an hour of sleep at a time. She sought medical advice in various quarters, and tried innumerable remedies in vain. At last she discovered that carbolic fomentations ( 1 in 100) gave more relief than any other application. Even with this she was obliged to rise up in the night every hour to apply a new dressing, and her whole life, day and night, was devoted to devising some method of alleviating pain for an hour or half an hour at a time. The pain was steady, with occasional sharp darts, and extended from the ulcers up to the spine; sbe indicated a position on the spine extending 3 inches below the second dorsal vertebra.

Condition when seen in Febrwary, 1909.-When the patient consulted me at St John's Hospital there were two ulcers, one on the rounded part of the left shoulder, the other 2 inches lower on the outer aspect of the arm. Both were about the size of a shilling, the lower slightly deeper, about one-third of an inch, with irregular raised margins and clean red bases. Two inches nearer the elbow, in a line with the ulcers, was a hard raised papule with a scab. This was picked off a few days later and revealed a small ulcer which in three days time enlarged to the size of a threepenny-bit. The patient explained that the upper two ulcers had begun in a similar fashion and she had not observed when the third nodule first made its appearance. The ulcers were situated on a band of thick sclerodermatous tissue which extended down as far as the middle of the forearm. This band varied in breadth from to $1 \mathrm{inch}$, and was surrounded by an area of white atrophied skin over which coursed large telangiectases. The first and second fingers of the left hand (which, as described above, had also been exposed to the $X$ rays) showed signs of chronic $X$ ray dermatitis of a mild degree-slight atrophy and telangiectasis, with brittleness of the nails, and the left cheek presented a slight mottling which was not seen on the other cheek. Similar atrophy with large telangiectases existed on the breast and thigh, the parts which had been exposed to the rays. Patches of morphœea (localised scleroderma) were present on the back and chest; some of these were white and thickened, some were pigmented, with a purple surrounding area, such as is frequently met with in association with morphoea, but none of those untreated areas had the marked degree of telangiectasis present over the areas which had been exposed to the $X$ rays.

Treatment.-After trying cocaine and other analgesic applications a week without any effect I asked my colleague, Dr. Alfred Eddowes, to see the patient and to take her into the hospital if he considered that an operation would yield good results in such a case. Dr. Eddowes considered that the only possible method of giving relief to the patient was to divide the nerves just before they entered the ulcerated areas. Accordingly, on Feb. 18th, 1909, he operated. A semicircular incision, about one inch deep, was made above each of the three ulcers. Another slightly shorter semicircular incision of the same depth was made across the centre of each ulcer. Free bleeding was encouraged; and the gaping wounds were stuffed with aseptic gauze and a fomentation applied. The gauze remained in for several days; it was left in situ until the granulation tissue, swelling up from the bottom of the wounds, pushed out the gauze before it. The gauze, therefore, was not removed until nature herself rejected it, and the wounds healed up slowly with abundant granulation tissue. The natural healthy discharge was not washed off with antiseptic lotions; a non-irritant boracic acid ointment with yellow paraffin basis was applied. The operation had an immediate result for the better on the patient's condition. Although a sleeping draught of chloral hydrate was administered for another week the patient stated that on the evening after the operation the pain had entirely altered in character, and she so rapidly improved that at the end of the week she was able to have a good night's rest without the administration of any hypnotic. During her residence in hospital injections of fibrolysin were given to bring about absorption of the extremely hard sclerodermatous condition of the arm. When the patient was discharged from the hospital after three weeks' residence the ulcers had almost healed up and were completely free from pain. Since that time (March) she has attended more or less regularly, at fortnightly intervals, the ont-patient department of the hospital. Although the operation had cured the pain and the ulcers had at once started to close complete healing did 